\title{
LA PROTECCIÓN DEL INTERÉS GENERAL POR PARTE DE LA ADMINISTRACIÓN Y DEL DERECHO ADMINISTRATIVO. (UN ESTUDIO DESDE LA TEORÍA JURÍDICA Y LA FILOSOFÍA POLÍTICA) ${ }^{1}$
}

\author{
M. ${ }^{\mathrm{a}}$ Isabel Garrido Gómez
}

\begin{abstract}
Sumario: 1. El nuevo ConteXto. 2. Consideración especial del DERECHO ADMINISTRATIVO. 3. LA CONSECUCIÓN DEL INTERÉS GENERAL POR PARTE DE LA ADMINISTRACIÓN. 4. LOS LÍMITES A LA ADMINISTRACIÓN Y LA PROTECCIÓN DEL INTERÉS GENERAL. 5. EL CONTEXTO TRANSFORMACIONAL TEÓRICO Y FILOSÓFICO DEL INTERÉS GENERAL CLÁSICO DESDE UN ENFOQUE GARANTISTA. 6. A MODO DE CONCLUSIÓN. 7. BIBLIOGRAFÍA.
\end{abstract}

\section{EL NUEVO CONTEXTO}

El punto de partida del análisis enunciado en el título de este estudio es que, hoy día, se ha producido una mutación en todos los órdenes y que los paradigmas de la modernidad ilustrada, aunque siguen teniendo mucho que decir, han planteado cuestiones lo suficientemente relevantes como para ser abordadas. Un ejemplo recurrente para valorar el nuevo contexto en el que nos movemos es el que nos muestra Arnaud, pudiéndose sintetizar en los siguientes niveles de análisis: a) Hay «un cambio de los modelos de producción dada por una dislocación de la actividad económica facilitadora de los traslados de una parte de las operaciones de trabajo de un país a otro», contribuyendo al surgimiento de una nueva división internacional laboral; b)

${ }^{1}$ Este trabajo ha sido realizado en el marco del Proyecto Consolider-Ingenio 2010 «El tiempo de los derechos» (CSD2008-00007), y del Proyecto «Derechos humanos, sociedades multiculturales y conflictos» (DER 2012-31771), ambos del Ministerio de Economía y Competitividad de España. 
«hay un desarrollo de los mercados de capitales establecidos más allá de las naciones», naciendo un flujo que no tiene en cuenta las fronteras; y c) «hay una creciente expansión de las multinacionales», que tiene «la posibilidad de aumentar en gran medida su producción, dado su poder negocial y de mercado en una economía a escala planetaria». Economía en la que concurre «la importancia creciente de los acuerdos comerciales entre naciones formando bloques económicos regionales de primer nivel»; «un ajuste estructural que engloba la privatización y la disminución del papel del Estado»; «la hegemonía de los conceptos neoliberales en materia de relaciones económicas»; «una tendencia generalizada en el mundo de la democratización, la protección de los derechos del hombre, así como un renovado interés por el Estado de Derecho»; y «la aplicación de actores supranacionales y transnacionales promotores de la democracia y la protección de los derechos del hombre» ${ }^{2}$.

Por otro lado, vistas así las cosas, se observa que existen instituciones que actúan como centros de poder económico, caso de la OMC, el FMI o el Banco Mundial -también la OCDE, o el G7-. En efecto, se puede afirmar que cada uno forma algo similar a un sistema global, en el cual son ellos los únicos responsables en la determinación de las reglas de funcionamiento, de su ejecución y del control de su realización por medio de un sistema de resolución de conflictos, dando lugar a un proceso de feudalización de la Administración y del Derecho administrativo. Así pues, esto nos conduce a mantener que la democracia es cada vez menos representativa, menos participativa y alcanza cotas menores de emancipación ciudadana ${ }^{3}$. Al hilo de estos aspectos, el desplazamiento de los poderes de decisión jurídica origina organismos, mecanismos y sistemas supranacionales de coordinación, a lo que se une que de estos procesos derive una pulverización de los cauces de legitimación democrática a favor de una legitimación técnica apoyada en exigencias de funcionamiento que son inherentes a la estructura del sistema ${ }^{4}$.

En definitiva, las fuerzas económicas han potenciado vías y formado organizaciones que escapan, al menos en su gran mayoría, del Estado. En esta dirección, se aprecia que los Estados-nación se van excluyendo progresivamente de los intercambios mundiales, cuya tendencia es a convertirse en transnacionales. Ahora bien, no debemos olvidar que el Estado-nación, a

2 ARnaud, A.-J. \& Fariñas Dulce, M. J., Sistemas jurídicos: Elementos para un análisis sociológico, trad. de la segunda parte R. EsCUDERO, Universidad Calos III de Madrid-Boletín Oficial del Estado, Madrid, 2006, pp. 280-281.

3 FARIÑAS, M. J., Globalización, ciudadanía y derechos humanos, Dykinson, Madrid, 2004, p. 26; GonZÁLEZ GARCÍA, J. V., «Globalización económica, Administraciones públicas y Derecho administrativo», Revista de Administración Pública, n. ${ }^{\circ}$ 164, 2004, pp. 14-15.

${ }^{4}$ Pérez Luño, A. E., Derechos humanos, Estado de Derecho y Constitución, Tecnos, Madrid, 2005, pp. 200 y ss. 
pesar de su carácter cada vez más degradado, sigue siendo un punto de referencia obligado. Desde otra perspectiva y en un sentido contradictorio, el movimiento contemporáneo de la globalización acarrea el interés hacia los procesos, identidades y unidades de análisis locales, conllevando un regreso de la sociedad civil cuya representatividad es creciente a la hora de la regulación social ${ }^{5}$.

Llegados a este punto, la pregunta que convendría hacernos es ¿cuál es el mayor problema que se debe tener en cuenta? Pues bien, a este respecto creo que la respuesta de Ferrajoli es muy certera. Según el autor, la credibilidad del Derecho ha entrado en crisis al mostrarse incapaz de dictar normas adecuadas para dar solución a los desafíos de la globalización. Ferrajoli describe la situación como «un vacío de Derecho público a la altura de los nuevos poderes y de los nuevos problemas, como la ausencia de una esfera pública internacional, es decir, de un Derecho y de un sistema de garantías y de instituciones idóneas para disciplinar los nuevos poderes desregulados y salvajes tanto del mercado como de la política ${ }^{6}$.

Asumiendo los anteriores postulados, no cabe duda de que la idea de la unificación del Derecho en la era de la globalización parte de que hay una nueva relación en las fronteras entre lo público y lo privado. Las Administraciones públicas recurren progresivamente al Derecho privado cuando proceden a la venta de sus activos y emplean la contratación para cumplir con las misiones que tienen encomendadas, prestando servicios de forma indirecta mediante las concesiones a empresas que son privadas, extrapolando a las empresas públicas fórmulas utilizadas en el Derecho privado o recurriendo a la constitución de fundaciones ${ }^{7}$. Esta asunción de contenidos tiene como consecuencia que se haya llegado a hablar de un Derecho común europeo con referencia al Derecho interno de los Estados de la Unión dictado para cumplir con una obligación establecida por las normas de Derecho comunitario ${ }^{8}$.

${ }^{5}$ ARNAUD, A. J., Entre la modernidad y la globalización, trad. N. GonZÁlez LAJOIE, Universidad Externado de Colombia, Bogotá, 2000, p. 37; LiMA, J., «Globalización y derechos humanos», Anuario de Filosofía del Derecho (España), t. XVII, 2000, p. 48.

${ }^{6}$ Ferrajoli, L., «Criminalidad y globalización», trad. M. CARbonell, Boletín Mexicano de Derecho Comparado, n. ${ }^{\circ} 115,2006$, p. 302.

${ }^{7}$ Furger, F., «Global Markets, New Games, New Rules: The Challenge of International Private Governance», en Appelbaum, R. P., Felstiner, W. L. F. \& Gessner, V., Rules and Networks. The Legal Culture of Global Business Transactions, Hart Publishing, Oxford, 2001, pp. 202 y ss.; ZAPATERO, V., El arte de legislar, Thomson-Aranzadi, Cizur Menor, 2009, pp. 376-377.

8 EstÉvEZ, J. A., «La globalización y las transformaciones del Derecho», en ZAPATERo, V. (ed.), Horizontes de la Filosofía del Derecho, Homenaje a Luis García San Miguel, vol. I, Universidad de Alcalá, Alcalá de Henares, 2002, p. 316; SousA SAnTos, B. de, Toward a New Common Sense: Law, Science and Politics in the Paradigmatic Transition, Routledge, Londres, 1995. 
Al mismo tiempo, cada vez más, aparecen normas sustitutorias de las nacidas del Estado liberal y el Derecho decimonónico. Tales normas se caracterizan por ser procedimentales y por servir para reforzar los criterios sociales de control, así su imperatividad es baja, pero no su coercibilidad. No obstante, todo no queda aquí, sino que la lectura de la complejidad anunciada inicialmente se traduce en que el Derecho se reprivatice. Por lo que retrocede el Derecho público, adquiriendo también la idea de la Constitución unos perfiles nuevos al adoptar la forma de «una carta de identidad política y cultural» y actuar como un centro de convergencia de valores en cuyo campo solo tendrían absolutividad, desde un punto de vista sustantivo, los derechos de la ciudadanía y el mantenimiento del pluralismo axiológico, por medio de la adopción de mecanismos neutralizadores de soluciones que siguen una línea homogeneizadora, y de medidas capaces de bloquear la libertad e instaurar una unidad social indiferenciada ${ }^{9}$.

Se puede decir que la globalización contemporánea está produciendo como una regresión del Derecho a las formas que estaban vigentes en la época premoderna. Los problemas más acuciantes son de naturaleza política, más que jurídica, y su origen se encuentra sobre todo en la falta de disposición de las grandes potencias y las grandes empresas multinacionales a someterse a los límites y vínculos que una esfera pública heterónoma llevaría en sí misma ${ }^{10}$. Se puede abogar, como Ferrajoli, por un constitucionalismo y un federalismo global sin Estado, lo que hace muy importante repensar el Estado y el orden internacional desde el punto de vista del constitucionalismo y del garantismo. Lo que para él significa las garantías que se necesitan frente a todos los poderes para que los derechos fundamentales sean tutelados normativamente en cada uno de los niveles, por eso se habla de un orden multinivel, de una democracia constitucional multinivel.

En consecuencia, los elementos estructurales de esta evolución se reservan a las Constituciones, por lo que se explica que en las que corresponden a un sistema de naturaleza rígida que reciben a los derechos humanos en cuanto normas del Derecho internacional general y consuetudinario, ese nivel supraordenado queda reforzado por formar un rango constitucional de las correspondientes normas de recepción. El segundo elemento se expresaría en el sentido de venir constituido por la jerarquía de las fuentes que viene dada por el cuadrilátero de las libertades. El tercer elemento guarda una relación con los anteriormente citados y se corresponde con una legislación que actúa el principio de la paz y los derechos fundamentales internacionalmente esti-

9 FARIA, J. E., El Derecho en la economía globalizada, trad. C. LEMA, Trotta, Madrid, 2004.

${ }^{10}$ Ferrajoli, L., Principia iuris. Teoría del Derecho y la democracia, trad. P. ANDRÉs IbÁÑez, J. C. BAYón, M. Gascón, L. Prieto \& A. Ruiz Miguel, Trotta, Madrid, vol. 2, 2011, pp. 538-539. 
pulados. El cuarto, también vinculado a los otros tres anteriores y no actuando de forma aislada sin ningún tipo de conexión, tiene relación con la primacía del Derecho internacional de las funciones y las instituciones y garantías en relación con las funciones de gobierno, unas y otras ligadas por una relación de subsidiariedad a las correlativas funciones de naturaleza estatal e infraestatal. El quinto posee naturaleza internacional y se traduce en la idea del federalismo explicado como multiplicación de los centros de poder y distribución de sus competencias entre varios niveles, centrales y periféricos ${ }^{11}$.

Similarmente, se puede subrayar que existen tres líneas de expansión por la lógica interna del constitucionalismo democrático, ellas son la siguientes: Un constitucionalismo político y social más rígido y garantizado, dada la crisis producida de la democracia política y del Estado social. Además, el Estado social se ha desarrollado no únicamente en las formas de las garantías constitucionales de los derechos sociales sino también en la de la expansión de los aparatos burocráticos, el crecimiento de su discrecionalidad política y la acumulación inorgánica de leyes especiales, medidas sectoriales, prácticas administrativas e intervenciones clientelares todas las cuales se exponen a la voluntad y a las políticas demoledoras de las mayorías. La tercera vía se extiende a las relaciones de Derecho privado ya que es necesario diferenciar dos dimensiones del constitucionalismo de Derecho privado: una es negativa y se traduce en el límite, que se impone a la autonomía privada, de la cuestión de que los derechos fundamentales y los bienes personalísimos son indisponibles. Y la otra es negativa y positiva y consiste en los límites y los vínculos impuestos a la propia autonomía por la garantía de los derechos fundamentales de otros, aparte de por bienes comunes y bienes sociales. Finalmente, la cuarta expansión del paradigma constitucional es la de un constitucionalismo supranacional ${ }^{12}$.

\section{CONSIDERACIÓN ESPECIAL DEL DERECHO ADMINISTRATIVO}

Según reza el título del estudio que tenemos entre manos, lo que nos interesa primordialmente es analizar qué representa el Derecho administrativo contemporáneo y cuál es su función a la hora de proteger el interés general. Atendiendo, por tanto, a esta cuestión, a primera vista lo más llamativo es la vinculación que muestran las transformaciones del Estado de Derecho y del Derecho administrativo, en el que las cláusulas abiertas y los conceptos jurídicos indeterminados aportan el soporte material sobre el que la discrecionalidad administrativa actúa, asumiendo grandes cotas de libertad ${ }^{13}$.

11 Ferrajoli, L., Principia iuris. Teoría del Derecho y la democracia, cit., pp. 540 y ss.

12 Ferrajoli, L., Principia iuris. Teoría del Derecho y la democracia, cit., pp. 80-84.

13 Ayres, I. \& Braithwaite, J., Responsive Regulation: Trascending the Deregulation Debate, Oxford University Press, Nueva York, 1992; y, en concreto, GonZÁlez 
Por otra parte, existe una fuerte incidencia de lo que Beck ha venido en denominar sociedad del riesgo. Esta encuentra su origen en el hecho de que la seguridad se confirma como un bien de consumo más, administrado pública y privadamente para llegar a obtener beneficios. De esta forma, si hay que catalogar un riesgo como peligro no aceptable, ello depende de intereses y no de cuestiones objetivas. La construcción de la seguridad, y el control del pensamiento social y la acción política en la primera etapa de la modernidad, se están haciendo ficticias en el entorno de la sociedad del riesgo global $^{14}$. Con estas coordenadas, nos hallamos ante un contexto social que no está responsablemente organizado. La misma sociedad que se mueve por intereses decide cuáles son los riesgos aceptables y cuáles son los peligros inadmisibles. Para hablar de ella, es preciso comenzar a conformar acciones y dar viabilidad a la creación de instituciones internacionales frente a los peligros globales ${ }^{15}$.

Así, la regulación actual no impone ya simples límites de mínimos, como ocurría en el siglo XIX, sino que establece una relación de requisitos condicionantes, razón por la que muchos hablan de un Derecho administrativo neopolicia ${ }^{16}$. En este sentido, muchas veces se ha optado por reducir el campo de aplicación del Derecho administrativo a las esferas en las que resulta totalmente imprescindible a causa de que el Derecho privado no es aplicable para conseguir los fines del interés general. Tal cosa hace que perdamos en garantías, y esa pérdida puede ser causa de ineficiencias dado que el no tener un control adecuado de la actividad administrativa abre un cauce para el empleo incorrecto de los fondos públicos, el descontrol del gasto o la corrupción ${ }^{17}$. Prosiguiendo con el análisis de esta realidad, el hecho de que surja una huida hacia el Derecho privado gracias al propio legislador es una cuestión que nos debe hacer tomar conciencia de la realidad y examinar los campos que han quedado desfasados, proponiendo nuevas soluciones y buscando un nuevo equilibrio que se ajuste mejor a las necesidades de nuestra coyuntura con nuevas técnicas y nuevos instrumentos ${ }^{18}$.

GARCíA, J. V., «Globalización económica, Administraciones públicas y Derecho administrativo», cit., pp. 7 y ss.

${ }^{14}$ BeCK, U., La sociedad del riesgo global. Hacia una nueva modernidad, trad. J. NAVArRo, D. JimÉnez \& M. R. Borrás, PAIDÓS, Barcelona, 2008, pp. 221 y ss.

15 BECK, U., La sociedad del riesgo global. Hacia una nueva modernidad, cit., pp. 222-226.

${ }_{16}$ MiR, O., Globalización, Estado y Derecho. Las transformaciones recientes del Derecho administrativo, Civitas, Madrid, 2004, pp. 116 y ss.

${ }_{17}$ Desdentado, E., La crisis de identidad del Estado administrativo. Privatización, huida de la regulación pública y administraciones independientes, Tirant lo Blanch, Valencia, 1999, pp. 105-106 y 130-131.

${ }_{18}$ Mir, O., Globalización, Estado y Derecho. Las transformaciones recientes del Derecho administrativo, cit., pp. 240 y ss. Sobre el tema, ver también HEAD, M., Administrative Law. Context and Critique, The Federation Press, Sydney, 2008, pp. 50 y ss. 
A mi juicio, el camino de la pseudoprivatización que se ha iniciado por la Administración supone que, mediante el recurso a las formas organizativas o al régimen jurídico privado, hay una supuesta creencia de que el Derecho administrativo no es útil. En relación con lo expuesto, se sustenta que tal Derecho no sirve para llevar a cabo la actividad propia de la Administración, solamente aparece como un instrumento inservible para encauzar una actividad administrativa que satisfaga eficazmente los intereses públicos. Teniendo en cuenta todas estas consideraciones, se ha optado por la reducción del ámbito que compete al Derecho examinado. Únicamente le competiría la regulación de aquellas áreas que son imprescindibles, porque el Derecho privado se muestra como un medio alternativo para la consecución de fines de interés general.

Mas, ante la realidad escenificada, se percibe que la Administración es una organización de carácter instrumental. Por esta razón, es muy importante que las sociedades tengan un modelo administrativo que sirva de forma efectiva a los intereses públicos, y que el ordenamiento jurídico regulador establezca las vías y los pasos pertinentes para hacer que ello se logre. En consecuencia, se vendría a afirmar en un primer plano que la eficacia es uno de los principios básicos de la actuación administrativa, junto al de legalidad, conforme a lo previsto en el artículo 103 de la Constitución española. Empleando tales presupuestos, la Administración debe regirse por normas que prevean las vías de mayor eficacia dentro de sus posibilidades y del respeto al resto del ordenamiento jurídico, especialmente a los principios constitucionales. Los principios aludidos se catalogan, aparte de en el principio de legalidad, en el principio de interdicción de la arbitrariedad, el principio de objetividad, el principio de igualdad ante la ley, la libertad de concurrencia, el control del gasto público, la publicidad y transparencia, el acceso a la función pública conforme a los criterios de mérito y capacidad, la participación de los interesados en la adopción de las decisiones administrativas, y el respeto, promoción y protección de los derechos e intereses legítimos de los particulares. Sin embargo, aun aceptando que no haya una reserva general de Derecho administrativo, hay reservas parciales y límites y principios que, sea cual sea la legislación que regule la actividad administrativa, se deben garantizar ${ }^{19}$.

Pero los cambios no quedan aquí. También se constata la existencia de una modificación en lo que respecta a la discrecionalidad administrativa y a los actos políticos o de gobierno y de su control por los tribunales. En resumen, se trata de un Derecho administrativo «menos nacional, más garante y menos prestador, más democrático en unos aspectos y menos en otros, sometidos a un régimen jurídico que le concede mayores espacios de

19 Desdentado, E., La crisis de identidad del Estado administrativo. Privatización, huida de la regulación pública y administraciones independientes, cit., pp. 108 y 117. 
libertad $»^{20}$. Desde el punto de vista apuntado, el reto es alcanzar el desenvolvimiento de un entramado jurídico y político-institucional que pueda hacer frente a los obstáculos de la nueva sociedad global. De modo que es preciso crear nuevas estructuras políticas y administrativas que dispongan de un alcance planetario para regular los mercados globales y hacer que las normas se cumplan por los agentes económicos ${ }^{21}$.

En esta línea, no sería plausible eliminar la idea de que los poderes públicos deben asumir la iniciativa de efectuar medidas que logren la igualdad real mediante políticas redistributivas que superen las fronteras nacionales y reduzcan las desigualdades en el mundo globalizado. La dirección que se debería seguir, pues, es la de potenciar más la solidaridad y menos la competencia, ello es urgente ya que el mercado no puede arreglar la situación por sí solo $^{22}$. Si bien el que los diseños y planteamientos sean globales no significa que hablemos de una uniformización absoluta, sino todo lo contrario. Tanto la Administración como el Derecho administrativo deben tener en cuenta las particularidades locales, y remitirse a las instancias de decisión y ejecución que más cerca estén de los ciudadanos por ser materias de dimensión e interés local ${ }^{23}$.

Una última consideración es que se podría entrar a valorar también el ámbito del Derecho administrativo como autorregulación regulada. Esta viene representando una especie dentro del género de la desregulación consistente en la tolerancia por parte de los poderes públicos de las normas gestadas en el ámbito privado, pero con el objetivo de que tales normas cumplan fines de interés general. Con tal visión, la característica de la autorregulación regulada reside en la cooperación entre el Estado y los sujetos económicos privados que tiene como fin el cumplimiento más eficaz y eficiente de los intereses generales ${ }^{24}$.

${ }^{20}$ Alli, J. C., Derecho administrativo y globalización, Civitas, Madrid, 2004; MIR, O., Globalización, Estado y Derecho. Las transformaciones recientes del Derecho administrativo, cit., pp. 184 y ss., y 207.

${ }^{21}$ Bradley, A. W. \& EwIN, K. D., Constitutional and Administrative Law, Pearson Education Limited, Essex, 2007, pp. 419 y ss.; Mir, O., Globalización, Estado y Derecho. Las transformaciones recientes del Derecho administrativo, cit., pp. 210-211.

${ }_{22}$ Desdentado, E., La crisis de identidad del Estado administrativo. Privatización, huida de la regulación pública y administraciones independientes, cit., pp. 142-143.

${ }_{23}$ Mir, O., Globalización, Estado y Derecho. Las transformaciones recientes del Derecho administrativo, cit., pp. 208-214 y 220; y sus remisiones, entre otras, a las obras de BECK, U., ¿Qué es la globalización? Falacias del globalismo, respuestas a la globalización, trad. B. Moreno \& M. R. Borrás, PAIDÓS, Barcelona, 2008; DElmas-MARTY, M., Trois défis pour un droit mundial, Seuil, París, 1998; STIGLITZ, J. E., El malestar en la globalización, trad. C. RodRíGUEZ BRAUN, Taurus, Madrid, 2010.

${ }^{24}$ Marcilla, G., «Desregulación, Estado social y proceso de globalización», Doxa, n. ${ }^{\circ} 28,2005$, pp. $246-248$. 


\section{LA CONSECUCIÓN DEL INTERÉS GENERAL POR PARTE DE LA ADMINISTRACIÓN}

De lo hasta ahora reflexionado se deduce que el interés es la noción que sirve para denotar la adaptación o inadaptación efectiva de los diversos componentes de una relación jurídica, y de ella a los diversos supuestos de la realidad. Corrigiendo la generalidad de las fórmulas de la estructura sin reemplazarlas, las dota de un contenido concretizador y nos da a conocer a cuál de las partes se la puede, o debe, dar la razón.

Por tanto, si realizamos una división clásica en dos compartimentos estancos, el elemento de la relevancia, que en apariencia es excesivamente radical, demuestra que en realidad lo único que se produce es una mayor o menor trascendencia pública de las garantías jurídicas, siendo sumamente difícil concebir una hipótesis de un interés individual que no tenga alguna consecuencia de este tipo. En este orden de ideas, podemos sostener que, puesto que el mundo exterior posee un valor, constituye un bien y, en cuanto es objeto de una tendencia o de una aspiración de la persona hacia él, constituye un interés ${ }^{25}$.

Sin embargo, estos criterios son deficientes o, al menos, no son los únicos que interesan ni a los ciudadanos ni al propio legislador. En el nuevo contexto, a ellos les preocupa cada vez más la efectividad de las normas, porque el legislador no las dicta con el simple propósito de modificar o reafirmar los comportamientos (o los sentimientos, en las simbólicas) de los ciudadanos. Para el legislador, los comportamientos son medios para alcanzar un estado de cosas, por lo que la norma pueda ser eficaz (obedecida) pero inefectiva (no consigue el objetivo perseguido). La eficacia tiene que ver con la actitud positiva o negativa que ante la misma adopten los ciudadanos; y la efectividad depende de que quien haya tomado la decisión normativa haya establecido correctamente la relación causal entre la conducta que se demanda a los ciudadanos y el resultado que se persigue.

En este apartado creo necesario, por tanto, desglosar lo que significa el término eficacia, que es sumamente ambiguo, pudiendo seguirse dos clases de criterios: a) La conexión entre el Derecho como técnica de control social y las conductas que llevan a cabo los sujetos; y b) el nivel de incidencia de las normas en las conductas de los sujetos. En relación al primero, la correspondencia citada es un aspecto de la relación semántica entre un contenido de

${ }^{25}$ Desde un punto de vista lingüístico, ver CASARES, J., Voz «Interés», en Diccionario ideológico de la lengua española, G. Gili, Barcelona, 1992. Habermas delimita el sentido filosófico del termino al afirmar que «el interés presupone una necesidad o genera una necesidad» (Habermas, J., Conocimiento e interés, trad. M. JimÉnEz Redondo, Universidad de Valencia, Valencia, 1995). Y, desde la perspectiva de la Jurisprudencia de intereses, ver Heck, P., El problema de la creación del Derecho, trad. M. ENTENZA, Comares, Granada, 1999, pp. 60 y ss. 
proposiciones y un estado de cosas. En lo atinente al segundo, la relación implica que existe un sistema normativo, no pudiendo definirse la eficacia en el nivel de correspondencia entre acciones y prescripciones, integrando, a su vez, las condiciones precisas de la existencia del sistema ${ }^{26}$.

Debido a todo lo que acabamos de decir, se podrían alcanzar, con palabras de P. E. Navarro y C. Redondo, una serie de conclusiones: a) Un concepto de eficacia que sea útil en el ámbito de la Teoría general del Derecho se ha de relacionar de forma lógica con el concepto de prescripción; b) el punto de enlace entre eficacia y prescripción precisa, además de la correspondencia, un elemento contrafáctico en cuanto a la incidencia de los sistemas normativos; c) la conceptuación de la eficacia en relación con los enunciados de correspondencia no expresa la naturaleza normativa de los sistemas jurídicos; y d) la unión del concepto de eficacia con los motivos de los sujetos sirve como criterio valorativo de la actuación de los sistemas jurídicos, manifestando que aquella cuestión no se desenvuelve con una concienciación de la situación de las cosas en su adecuación a los contenidos normativos ${ }^{27}$.

Un último parámetro con el que los ciudadanos juzgan cada vez más las normas es el de la eficiencia. En un contexto de escasez, el legislador racional ha de perseguir los resultados deseados al menor coste posible, «gobernar mejor con menores costes» es una exigencia de los ciudadanos de cualquier país si es verdad que la eficiencia es una condición, aunque deficiente, de la justi$\mathrm{cia}^{28}$. El jurista tradicional se ha ocupado poco de la eficacia de las normas y muy raramente de su efectividad y eficiencia, pese a ser parámetros de necesaria consideración y cuyas diferencias no ha destacado suficientemente la ciencia jurídica. Centrado en el estudio de la validez de la norma, y como mucho de su eficacia, no ha prestado atención a que la posible quiebra de este mecanismo de control social que es el Derecho no proviene solo, ni fundamentalmente, del grado de obediencia o desobediencia, sino de la sospecha que se ha instalado en nuestras sociedades de que las normas son, a veces, escasamente efectivas, así como del temor a que sus costes no se conozcan o que, cuando se sepan, superen las ventajas prometidas. En suma, aunque no hay que perder de vista que detrás de tales críticas suele haber un intento de justificar políticas neoliberales de desregulación, crece la sospecha de que el Derecho es un instrumento

${ }^{26}$ Navarro, P. E. \& Redondo, M. C., Normas y actitudes normativas, Fontamara, México, 2000, pp. 22 y ss.; Zapatero, V., Garrido, M. I. \& Arcos, F., El Derecho como proceso normativo. Lecciones de Teoría del Derecho, Universidad de Alcalá, Alcalá de Henares, 2010, pp. 20-21.

${ }^{27}$ Navarro, P. E. \& Redondo, M. C., Normas y actitudes normativas, cit., pp. 29-30.

28 Calsamiglia, A., «¿Debe ser la moral el único criterio para legislar?», Doxa, n. ${ }^{\circ} 13,1993$, pp. 69 y ss. Sobre el tema de la eficiencia, ver también CALSAMigLiA, A., «Eficiencia y Derecho», Doxa, n. ${ }^{\circ}$ 4, 1987, pp. 267-287; Hierro, L., Justicia, igualdad y eficiencia, Centro de Estudios Políticos y Constitucionales, Madrid, 2002, pp. 63 y ss. 
de control social demasiado tosco y costoso que no siempre proporciona lo que se le pide.

Pero no todo queda aquí, sino que, cuando hablamos de la eficacia o de la eficiencia, nos referimos a sus efectos y consecuencias a pesar de la diferencia que hay entre ambos conceptos. En tal sentido, pienso que es subrayable la postura de Nino, quien aprecia que hay una cierta correspondencia entre ambos conceptos dentro la norma jurídica en el supuesto de que su cumplimiento desemboque en una suma agregada de mayor nivel en la satisfacción de preferencias, descontando la frustración de preferencias. Siendo relevante en este punto la idea de que Nino identifique a la eficacia con la anomia y, singularmente, con la que afecta a valores trascendentales del Estado de Derecho ${ }^{29}$.

En vista de lo aducido, en el caso de que partamos de la eficacia como un principio jurídico consagrado en el artículo 103 de la Constitución española, se establece la consecución en cada momento histórico del interés general y de su efectividad. Y hablamos de interés general como «la aglutinación de intereses, valores o bienes concretos susceptibles de ser protegidos». Sin embargo, para realizar satisfactoriamente el mandato previsto en el artículo 103 , se ha de ponderar, evaluar y analizar el coste-beneficio de algunas reglas, analizando cuál de las decisiones es la que optimiza el objetivo/objetivos que se ha/han de conseguir. Por consiguiente, si queremos superar la mera eficacia y alcanzar también la eficiencia, hemos de tener en cuenta que, aparte de entender que algo ha de ser realizable, también ha de haber alcanzado todas las metas para llegar a desplegar la mejor decisión con los programas de financiación y periodicidad presupuestaria ${ }^{30}$.

Mas el nuevo escenario supera la comprensión del interés general en el Estado social de Derecho que implica un nivel en el que se evalúan como instrumentos jurídicos del control de la actividad positiva que debe estar canalizada hacia la participación de los individuos y los grupos cuando actúa el poder. Lo que simboliza la aparición del Estado social de Derecho es la extensión de la protección de las libertades y derechos fundamentales a aquellos que antes no habían podido gozarlos. Por esta razón, se sostiene que tal Estado fortalece la conexión entre la libertad y la solidaridad, valores que antes se contraponían, debido a que las garantías de la libertad individual recaen en las formaciones sociales en las que los ciudadanos desenvuelven su personalidad.

En definitiva, el aspecto positivo es lograr una mayor estabilidad y cohesión que los Estados liberales, integrando metas de justicia social, perfeccionadas, más eficientes y adaptadas a las nuevas circunstancias y necesidades,

${ }^{29}$ NINO, C. S., Un país al margen de la ley. Estudio de la anomia como componente del subdesarrollo argentino, Ariel, Buenos Aires, 2005, pp. 35 y ss.

${ }_{30}$ Montoro, M. J., La evaluación de las normas. Racionalidad y eficiencia, Atelier, Barcelona, 2001, p. 81. 
punto en el que hay que profundizar, ya que la crisis de esta clase de Estado reside en la protección que otorga a sus ciudadanos-clientes-beneficiados y en la exclusión que en muchos terrenos se confiere a los inmigrantes, los parados y las minorías ${ }^{31}$. El Estado social de Derecho, aun haciendo referencia a la estructura estatal, se ha de comprender de manera más rigurosa como orientación política enderezada a la obtención de una dimensión innovadora de la libertad. Lo que en realidad se pretende alcanzar es un avance de la libertad en la concepción liberal y en la democrática, una esfera de autonomía del individuo frente al Estado o un mecanismo de participación.

Con esta visión, la pregunta es ¿cuál es la función social que ha de desempeñar el Derecho dentro del ámbito que nos interesa? En un plano generalista, dos son las respuestas según se adopte la concepción funcionalista o la conflictualista de la sociedad. Quienes parten de una concepción funcionalista estiman que la misión del Derecho consiste en mitigar los elementos potenciales de conflicto y lubricar el mecanismo de las relaciones sociales ${ }^{32}$. Lo conciben como un sistema de control social o conjunto de procedimientos y de medios para que los ciudadanos adopten ciertos comportamientos, asuman e interioricen normas y alcancen las metas propuestas por el grupo social ${ }^{33}$. La integración del individuo se realiza con la socialización que, ante su insuficiencia, recurre a otros instrumentos para que la conducta se conforme ${ }^{34}$, viniendo a ser el Derecho ese instrumento que interviene para prevenir y/o reprimir las conductas no deseadas, y para promocionar y/o premiar las socialmente queridas.

No obstante, fuera de este enfoque forzosamente abstracto del Derecho cuando se le considera como un sistema de control social, una perspectiva funcionalista tiene que ocuparse de sus funciones sociales, distando los resultados conseguidos de ser satisfactorios y soliendo proponerse un listado heterogéneo de funcionalidades ${ }^{35}$. En este orden de ideas, no parece probable

31 VIDAL, E. J., Los conflictos de derechos en la legislación y jurisprudencia españolas. Un análisis de algunos casos difíciles, Tirant lo Blanch, Valencia, 1999, pp. 368-369. Ver además López GuerRA, L., «Las dimensiones del Estado social de Derecho», en Sistema, n. ${ }^{\circ}$ 38-39, 1980, pp. 171-192.

32 Treves, R., La Sociología del Derecho. Orígenes, investigaciones, problemas, trad. M. AtienzA, Ariel, Barcelona, 1998.

33 DíAz, E., Sociología y Filosofía del Derecho, Taurus, Madrid, 1993, pp. 14 y ss.

${ }^{34}$ Merton, R. K., Social Theory and Social Structure, Free Press, Glencoe, 1968. Según Merton la sociedad fija a los individuos una serie de objetivos y medios lícitos para alcanzarlos. Dada la relación entre los fines y la disponibilidad de los medios para obtenerlos, la acción del individuo puede ser conforme, desviante (en sus versiones de innovadora - que acepta los fines pero no los medios-y ritualista - que acepta los medios pero no los fines-) o rebelde.

${ }^{35}$ BobBio, N., «El análisis funcional del Derecho: tendencias y problemas», en BoBBIO, N., Contribución a la Teoría del Derecho, edic. de A. Ruiz Miguel, Debate, Madrid, 1990, pp. 272-273. 
que un listado común se pueda abstraer del examen de los distintos sistemas normativos. La generalidad de las respuestas que el planteamiento tiene que suministrar solo puede ser eliminada estudiando las funciones específicas que cumple un sistema normativo. Por eso, parece mucho más útil analizar la funcionalidad de cada uno y, más concretamente, de cada norma o institución. O sea, los objetivos perseguidos, su mayor o menor efectividad, las disfunciones $\mathrm{y} / \mathrm{o}$ funciones negativas que se generen y las funciones no declaradas, pero reales, de cada sistema, institución o norma ${ }^{36}$ que, en un Estado social de Derecho, ha de materializarse en base a políticas redistributivas e intervencionistas, en las que es relevante la aportación de una garantía de niveles mínimos de igualdad material, surgiendo un Derecho regulador que asume las funciones de control, gestión y dirección de los mercados ${ }^{37}$.

Por eso, el Estado social desempeña las funciones de Estado-empresario y distribuidor. Su realización conlleva que el Estado, sin eliminar la economía de mercado, regule, oriente y dirija el proceso económico ${ }^{38}$. En este sentido, lo que se pone de manifiesto es que los derechos sociales que se reconocen y protegen por el Estado son los que permiten que las personas que carecen de recursos satisfagan sus necesidades básicas. El concepto de necesidad se posiciona entre las nociones de supervivencia y abundancia de las que se derivan niveles de subsistencia y de vida decente en relación con el nivel de vida general de una comunidad. De ahí que se hable de derechos de libertad porque tienen como meta crear las condiciones para el pleno desarrollo de la autonomía; y de ahí que los derechos sociales sean incluibles dentro de los derechos participativos, pues determinan una participación en los beneficios del progreso de la vida social. En este orden de ideas, los poderes públicos tienen la responsabilidad de proporcionar a los ciudadanos las prestaciones imprescindibles para que desplieguen su personalidad y se integren socialmente, eliminando el abstencionismo ${ }^{39}$.

${ }^{36}$ GINER, S., Sociología, Península, Barcelona, 2009.

37 Julios-CAMPUZANO, A. de, «La crisis del ordenamiento. Reflexiones sobre racionalidad jurídica y globalización», en Julios-CAMPuZANO, A. de (ed.), Ciudadanía y Derecho en la era de la globalización, Dykinson, Madrid, 2007, p. 79; RÚA, C., «La legitimidad en el ejercicio del poder político en el Estado social de Derecho. Una revisión desde el caso colombiano», en Ius et Praxis, n. ${ }^{\circ} 2,2013$, pp. 85 y ss.

38 FERnÁNDEZ García, E., «Estado, sociedad civil y democracia», en Asís RoIG, R. de, Fernández García, E., González Ayala, M. D., Llamas, Á. \& Peces-Barba, G., Valores, derechos y Estado a finales del siglo XX, Universidad Carlos III de Madrid-Dykinson, Madrid, 1996, pp. 93-94; SMArT, P., Mill and Marx, Individual Liberty and the Roads to Freedom, Manchester University Press, Manchester, 1991.

39 AÑón, M. J., Necesidades y derechos. Un ensayo de fundamentación, Centro de Estudios Constitucionales, Madrid, 1994, pp. 261 y ss.; BEEN, S. I. \& PeTERS, R. S., Los principios sociales y el Estado democrático, trad. R. J. Vernengo, Edit. Universitaria de Buenos Aires, Buenos Aires, 1984, pp. 164 y ss.; BobBIo, N., Igualdad y libertad, trad. P. 
Pero ahora el Estado tiene que desarrollar su vida dentro de unos parámetros cada vez más complejos y a él le corresponde asegurar la mejor regulación posible en el ámbito social por medio del Derecho y de las políticas públicas, siendo sus funciones más acuciantes las de hacer que mejore el funcionamiento del mercado, la promoción de la igualdad y la protección de los trabajadores vulnerables ${ }^{40}$.

\section{LOS LÍMITES A LA ADMINISTRACIÓN Y LA PROTECCIÓN DEL INTERÉS GENERAL}

La versión que hemos estado analizando hasta ahora del modelo de protección del interés general por parte de la Administración y del Derecho administrativo conduce a que lo primero que se deba tener en cuenta sea el control de los hechos determinantes, pues toda acción discrecional de la Administración se apoya en una realidad fáctica que actúa como supuesto de hecho de la norma que ha de aplicarse ${ }^{41}$. Las resoluciones de la Administración se deben diferenciar por estar sometidas al principio de legalidad y por ser discrecionales, consecuentemente, la cuestión es saber encontrar un plano intermedio en el que se respeten los dos principios. Con este objeto, se ha precisado que el margen de discrecionalidad para que haya eficacia ha de usarse con arreglo a los fines que persiga la actividad, de forma que son atacables los actos que, llevándose a cabo en el seno de los poderes que la ley reconoce, se dirijan a un fin que sea distinto del que en principio se determinó, figura que se conoce con el nombre de desvío de poder, o supongan una medida innecesaria o desproporcionada para alcanzar esos fines, es decir, exceso de poder ${ }^{42}$.

ARAGÓn Rincón, Paidós-Instituto de Ciencias de la Educación de la Universidad Autónoma de Barcelona, Barcelona, 2000, p. 47; FERNÁNDEZ GARCÍA, E., «Estado, sociedad civil y democracia», cit., pp. 106-110; GARCÍA-PElAYo, M., Las transformaciones del Estado contemporáneo, Alianza, Madrid, 2005, pp. 18 y ss.; Gilbert, N. \& Terrell, P., Dimensions of Social Welfare Policy, Allyn \& Bacon, Needham Heights, 2002, pp. 13 y ss.; Pérez LuÑo, A. E., Derechos humanos, Estado de Derecho y Constitución, cit., p. 230; Prieto, L., Ley, principios, derechos, Dykinson, Madrid, 1998, pp. 73 y ss.; TuORI, K., Positivismo crítico y Derecho moderno, trad. D. Mena, Fontamara, México, 2005, p. 22.

40 Arnaud, A. J. \& Fariñas, M. J., Sistemas jurídicos: Elementos para un análisis sociológico, cit., p. 282.

${ }^{41}$ GARCÍA DE ENTERRÍA, E., La lucha contra las inmunidades del poder en el Derecho administrativo. (Poderes discrecionales, poderes de gobierno, poderes normativos), Civitas, Madrid, 1995, pp. 31-49; en el mismo sentido García DE EnTERría, E., Democracia, jueces y control de la Administración, Civitas, Madrid, 2000.

${ }^{42}$ BARry, N. (ed.), Limited Government, Individual Liberty and the Rule of Law, Selected Works of Arthur Asher Shenfield, E. Elgar, Cheltenham, 1998; LATORRE, Á., Introducción al Derecho, Ariel, Barcelona, 2006, pp. 167-168. 
De la misma manera, se establecen una serie de requisitos que se deben cumplir, siendo el primero el de la motivación de las decisiones adoptadas para impedir el capricho o la pura subjetividad del órgano que las dicta, aunque tal motivación puede ser sucinta siempre que sea suficientemente indicativa. Otro requisito es el de la justificación objetiva, esto es, las decisiones tienen que venir respaldadas por los datos objetivos sobre los que operan ya que en los actos discrecionales, al concurrir cierta libertad estimativa, resulta de gran trascendencia el proceso lógico que conduce a la actuación decisional. Lo que hace que la Administración haya de aportar todo el material probatorio que acredite que aquellas se apoyan en una realidad fáctica garante de la legalidad y la oportunidad, sin olvidar la congruencia con los motivos y fines. Además de que la presunción de legalidad de los actos administrativos pretende garantizar su ejecutabilidad y evitar que, dada la oposición de un particular, se produzca su paralización trasladando al afectado la carga de impugnarlos y de promover el proceso ${ }^{43}$.

Pues bien, en la discrecionalidad administrativa plena la Administración debe estar autorizada por el ordenamiento jurídico para desarrollar sus actividades, pero puede suceder que, adjuntamente a la autorización, la faculte para decidir la solución que crea más conveniente en aras del interés público. Satisfacción que constituye uno de los fines del Estado y que justifica la organización administrativa, remitiendo a su estimación las condiciones que no sean regladas y estén enfocadas a la integración del supuesto de hecho, al contenido dentro de los límites de la decisión aplicable o a los dos elementos. Por tanto, el dato decisivo que plantea una potestad discrecional de esta categoría se apoya en las materias de naturaleza política sobre las que se ha de actuar según criterios de conveniencia y oportunidad ${ }^{44}$.

Como sabemos, un elemento limitador es el del control ejercido a través de los principios generales del Derecho, comprendidos como condensación de los valores superiores del ordenamiento jurídico, que en el caso de España son la libertad, la justicia, la igualdad y el pluralismo político (art. 1.1 de la CE). En este espacio, el mandato de los principios recae en imponer un genérico deber negativo que prohíbe actuar en contra del valor que consagran, pues no pueden crear obligaciones ni otorgar derechos subjetivos típicos o activos. En tal sentido, en cuanto a lo que se refiere a las Administraciones públicas, estas no pueden ejercer acción alguna si la ley vigente no ha delimitado antes los supuestos de hecho en los que puede ejercer como poder público que es, en

${ }^{43}$ Fernández Rodríguez, T. R., De la arbitrariedad de la Administración, Civitas, Madrid, 1999, pp. 82-92.

${ }^{44}$ Alessi, R., Principi di diritto amministrativo, t. I, Giuffrè, Milán, 1971, pp. 198 y ss.; García de EnTERría, E. \& Fernández, T. R., Curso de Derecho administrativo, t. I, Civitas, Madrid, 1999, pp. 478 y ss.; SAINZ, F., Conceptos jurídicos, interpretación y discrecionalidad administrativa, Civitas, Madrid, 1976, pp. 347 y ss. 
razón de que la configuración del régimen de atribución de potestades con arreglo al principio de legalidad precisa que se determinen a priori los supuestos fácticos en los que la Administración posee competencia. Mas, a mi juicio, el esquema anterior debe superarse porque concurren otras razones de índole práctica. Dentro de esa explicación, se sitúa la imposibilidad material de satisfacer todas las pretensiones que se legitiman en que la comunidad considera valioso que el Estado garantice la realización de un fin ${ }^{45}$.

Hoy, con la vigencia de los Estados constitucionales de Derecho, el tradicional principio de legalidad que regía la libertad del ciudadano y la acción de la Administración han cambiado también. En cualquier caso, la labor encomendada no es la misma que antaño, advirtiéndose que la Administración pública suele ser la gran realizadora de la política social. Sin embargo, desde hace tiempo, las cada vez más abundantes necesidades y la desproporción de los recursos han inducido a ciertos replanteamientos, barajando principios de solidaridad e igualdad, evaluados según el grado de desarrollo de la libertad que posibiliten, promoviendo la participación y la vinculación de los sujetos y de los grupos como sujetos de servicios primarios y como sujetos activos y transaccionales en los aspectos sociales que les afectan.

Congruentemente, el debate de la acción administrativa se encamina hacia la redefinición y fijación de límites para establecer un nivel mínimo de protección, que consiste en la prestación de los servicios indispensables para la integración en la sociedad y el apoyo a la promoción del bienestar. En suma, la polémica recae en que no hay un único camino de colaboración entre lo público y lo privado en las sociedades avanzadas, y en que las formas de colaboración responden a pautas culturales e institucionales que sobrepasan las fronteras de los Estados ${ }^{46}$.

En este marco y con la consideración de los enunciados anteriores, se supera la labor meramente garantizadora de antaño y se asumen tareas de gestión directa de grandes intereses públicos. Esa labor gestora requiere aparatos organizativos que efectúen las tareas según su propia lógica, determinada, como nos ilustra Zagrebelsky, por reglas empresariales de eficiencia, exigencias objetivas de funcionamiento e intereses sindicales de los empleados, por no hablar de las reglas informales que vienen dadas por los partidos políticos. A esto es a lo que se llama legislatividad de la organización ${ }^{47}$, la cual, en razón de la dificultad que supone regular previamente la actuación administrativa, ha de permitir programaciones concertadas, negociadas y flexibles.

${ }^{45}$ BeladíEz, M., Los principios jurídicos, Tecnos, Madrid, 1994, pp. 84-88.

${ }^{46}$ Garrido, M. I., La política social de la familia en la Unión Europea, Dykinson, Madrid, 2000, pp. 137-141.

47 Zagrebelsky, G., El Derecho dúctil. Ley, derechos, justicia, trad. M. Gascón, Trotta, Madrid, 2009, pp. 34-35. 
La regulación de las interioridades técnicas de la industria desde la Administración es materialmente imposible por la falta de conocimiento especializado. Cuanto mayor sea la pretensión reguladora, mayores serán los espacios de autorregulación ${ }^{48}$. En este caso, nos topamos también con regulaciones paralelas a los Derechos estatales, a título ilustrativo, las que provienen de la sociedad civil cuyo principal ejemplo es la lex mercatoria ${ }^{49}$.

\section{EL CONTEXTO TRANSFORMACIONAL TEÓRICO Y FILOSÓFICO DEL INTERÉS GENERAL CLÁSICO DESDE UN ENFOQUE GARANTISTA}

La crisis simultánea del Estado de Derecho, del Estado social y del Estado nacional impone una reflexión sobre las sedes del constitucionalismo, planteándose el problema de la democracia y de los derechos fundamentales por el absolutismo de la soberanía externa de los Estados, al igual que por el neoliberalismo de los poderes económicos financieros de naturaleza transnacional ${ }^{50}$. La puesta en práctica de un garantismo y constitucionalismo internacionales parece difícil de obtener, junto a la construcción de una esfera pública global. Pero hay un salto en lo que se refiere a las posiciones kantiana y kelseniana gracias al Derecho internacional vigente, profundizando en la crítica moral o política, pero también jurídica de las relaciones internacionales. Sin olvidar lo que puede aportar la cultura jurídica de donde es posible que se desarrolle un nuevo sentido común en torno a la ilegitimidad del orden existente y del carácter vinculante del Derecho internacional, constituyendo el primer factor de efectividad de los derechos que se reconocen por él ${ }^{51}$.

Otro tema interesante es el referido a la ciudadanía, habiendo de divisar los planos en el discurso referentes a la Teoría del Derecho, a la Filosofía política o de la justicia, y habiendo de estar basados los derechos fundamentales en la categoría de la persona y de la capacidad de obrar y no en la categoría de la ciudadanía. Una noción como esta de los derechos fundamentales es una noción de Filosofía política normativa que enuncia el deber ser externo del Derecho. Sin embargo, en el caso de que la cuestión la traslademos al campo de la definición de la Teoría del Derecho, entonces nos situaremos

${ }^{48}$ Esteve Pardo, J., Autorregulación. Génesis y efectos, Thomson-Aranzadi, Cizur Menor, 2002, pp. 26-29.

49 Esteve Pardo, J., Autorregulación. Génesis y efectos, cit., pp. 129 y ss.

${ }^{50}$ Ferrajoli, L., «Los fundamentos de los derechos fundamentales», en CABo, A. de \& Pisarello, G. (eds.), Los fundamentos de los derechos fundamentales, trad. P. Andrés ibáñez, A. de Cabo, M. Carbonell, L. Córdova, M. Criado \& G. Pisarello, Trotta, Madrid, 2009, p. 373; Ferrajoli, L., Derechos y garantías. La ley del más débil, trad. P. ANDRÉs IBÁÑEZ \& A. GREPPI, Trotta, Madrid, 2010, p. 115.

51 Ferrajoli, L., Garantismo. Una discusión sobre Derecho y democracia, trad. A. GREPPI, Trotta, Madrid, 2009, pp. 115 y ss. 
dentro de una noción que carece de alcance empírico y de capacidad explicativa, ya que no dará cuenta de los derechos fundamentales que en los Derechos positivos vigentes están construidos sobre la base de la ciudadanía siguiendo la estela de una cultural jurídica determinada. Pero lo cierto es que, en las democracias constitucionales, el escenario se puede ampliar más al fundamento de una crítica externa de tipo ético-político, dado que la ciudadanía opera como un factor de exclusión evidente. Lo cual contrasta con su acción inicial de igualdad e inclusión. En lo que respecta a la crítica interna, existe un derecho a emigrar y a inmigrar, por lo que la normativa debería ser reconocer esta cuestión y no ser restrictiva. Lo que no significa decir que no debe ser regulada esta materia, sino que debe ser regulada con miras a favorecerla ${ }^{52}$.

El constitucionalismo jurídico y, por ello, el de la democracia, viene dado por una triple expansión: hacia un constitucionalismo social, añadido al liberal; hacia un constitucionalismo de Derecho privado, agregado al de Derecho público; y hacia un constitucionalismo internacional, añadido al estatal ${ }^{53}$. La globalización ha hecho surgir el valor de las diferencias y de las identidades, y la misma forma del Estado es una amenaza para la paz, resultando más idóneas formas de organización política federales o confederales que descentralicen las funciones administrativas y de gobierno local que hoy están centralizadas en el Estado y asocian a dichos Estados en formaciones políticas más amplias a las que atribuyan las funciones públicas -legislativas, judiciales y administrativas- comunes a todos, en cuestiones de garantía de los derechos de libertad, política económica y monetaria, regulación del mercado, defensa del medio ambiente, redistribución de recursos y seguridad frente a la criminalidad. Siendo así las cosas, Ferrajoli entiende que es necesaria la extensión del paradigma.

El Estado constitucional debe ir abandonando su connotación clásica de naturaleza territorial y hacerse global frente a los retos desterritorializados actuales. Encontrándonos con las teorías del constitucionalismo global o de la democracia cosmopolita. Al mismo tiempo, el Estado constitucional debe diseñar mecanismos que garanticen efectivamente los derechos sociales, desarrollando garantías para el constitucionalismo de la igualdad, capaz de actuar con mecanismos que se impulsan en el constitucionalismo de la libertad. Por otro lado, el constitucionalismo ha de extender su paradigma garantista hacia sedes que son diferentes de los poderes públicos. Desde esta perspectiva, ha de desarrollar un constitucionalismo de Derecho priva-

52 Ferrajoli, L., Garantismo. Una discusión sobre Derecho y democracia, cit., pp. 119 y ss.

${ }^{53}$ Ferrajoli, L., El garantismo y la Filosofía del Derecho, trad. G. Pisarello, A. J. Estrada \& J. M. DíAz Martín, Universidad Externado de Colombia, Bogotá, 2010, p. 178. 
do que haga hacer valer los derechos fundamentales también en las relaciones entre particulares ${ }^{54}$.

Los dos aspectos que según el autor se deben seguir para fortalecer un sistema constitucional global son el reconocimiento de la supraestatalidad de los derechos fundamentales con el establecimiento de mecanismos de garantía; y la disociación de los derechos fundamentales y los derechos de ciudadanía, impidiendo que se creen mecanismos de exclusión dados los flujos migratorios ${ }^{55}$. Pero las peculiaridades de la globalización se sintetizan en una creciente incapacidad de regulación por parte del Derecho. Ello se evidencia en que cada vez son más numerosas e incontroladas las violaciones por parte de los poderes públicos y privados, al igual que en el vacío de las reglas que disciplinan sus nuevas dimensiones transnacionales; y como descalificación, intolerancia y rechazo del Derecho puesto que los poderes políticos supremos, por legitimarse democráticamente, no se someten a reglas ni de Derecho internacional ni tampoco de Derecho constitucional ${ }^{56}$.

Avanzando más, la Teoría del Derecho presentada en Principia iuris pretende reconstruir el modelo teórico y normativo del Estado constitucional de Derecho con el objetivo de hacer evidentes sus principios y las divergencias entre las prácticas jurídicas y esos principios. Para Ferrajoli, la Teoría del Derecho posee una visión pragmática. Los paradigmas jurídicos son en la mayoría de las ocasiones el producto de las teorías y, en general, de las doctrinas jurídicas y políticas, por lo que se podría llegar a afirmar que la Teoría encierra un papel constituyente o constructivo.

La idea de Ferrajoli sobre la axiomatización de la teoría es que ella constituye uno de los rasgos centrales, si no es el más importante de todos. Desde esta perspectiva, la teoría formalizada refleja una aspiración de la filosofía de la ciencia del neopositivismo lógico presente aún en los años sesenta del siglo XX. Así, Principia iuris representa la continuación lógica de su obra Derecho y razón; y la teoría garantista parte de la idea que ya fue utilizada en Locke y en Montesquieu de que del poder se ha de esperar un potencial abuso en todo caso, el cual se debe neutralizar haciendo del Derecho un sistema de garantías, de límites y vínculos al poder para la tutela de los derechos. Por tanto, como dice M. Gascón, «el garantismo se opone al autoritarismo en política y al decisionismo en Derecho, propugnando, frente al primero, la

${ }^{54}$ CARBonell, M., «La garantía de los derechos sociales en la teoría de Luigi Ferrajoli», en CARbonell, M. \& Salazar, P (eds.), Garantismo. Estudios sobre el pensamiento jurídico de Luigi Ferrajoli, Trotta-Instituto de Investigaciones Jurídicas de la Universidad Nacional Autónoma de México, Madrid, 2009, pp. 171-172.

${ }_{55}$ Córdova, L., «Constitucionalismo democrático y orden global», en CARBonell, M \& Salazar, P. (eds.), Garantismo. Estudios sobre el pensamiento jurídico de Luigi Ferrajoli, cit., p. 458.

56 FerRAJOLI, L., «Los fundamentos de los derechos fundamentales», cit., pp. 380-381. 
democracia sustancial y, frente al segundo, el principio de legalidad; y por eso el Estado constitucional de Derecho es visto como el producto de la mejor ingeniería jurídica ${ }^{57}$. La Teoría del Derecho se conforma como un espacio en el que los diferentes enfoques convergen, aportando una base conceptual con un sentido común ${ }^{58}$.

La formulación teórica del concepto de los derechos fundamentales en Ferrajoli debe ser analizada en relación a su capacidad explicativa y sobre su eficiente distinción entre los planos de la Teoría general del Derecho, la Teoría especial de los derechos fundamentales, la Dogmática jurídica y la Filosofía política. Desde este punto de vista, entiende Ferrajoli que existen distintos significados del término fundamento, que pueden ser de naturaleza teórica, jurídica, axiológica o histórica, y respecto de los cuales corresponde una clase de discurso diferente, ya sea teórico, jurídico axiológico o histórico-sociológico. Y se ha mantenido que la discusión sobre el contenido de los derechos pertenece al nivel de la Dogmática constitucional y de la Filosofía política y no de la Teoría del Derecho ${ }^{59}$.

Sin embargo, se puede apreciar que la concepción iuspositivista de Ferrajoli ve de forma indiferente el contenido de los derechos fundamentales a efectos de su positivización pero los convierte en casi intocables, constituyendo el resultado de procesos históricos contingentes. Por otro lado, si intentamos encontrar alguna relación con otros profesores de la doctrina, podemos afirmar que la concepción pluralista y conflictualista, pero también liberal, de Ferrajoli se acerca al liberalismo pluralista de John Gray. Así, Gray indica que es factible distinguir dos tendencias en los orígenes de la tolerancia liberal moderna: la tolerancia es la persecución de una forma de vida ideal; y es la búsqueda de un compromiso de paz entre diferentes modos de vida. Dentro del primer grupo, las instituciones liberales se conciben como aplicaciones de principios universales; y dentro del segundo son un medio para lograr la coexistencia pacífica.

Ferrajoli y Gray dudan del consensualismo moral porque sostienen que, en los hechos, no todos compartimos los mismos valores. Así las cosas, los derechos fundamentales son también una construcción humana ${ }^{60}$. La importancia de la propuesta de Ferrajoli radica en su intento de reformular el Estado social. Repensar el Estado social en la forma del Estado constitucional de

${ }^{57}$ GASCÓN, M., «Principia iuris: caracterización de una teoría jurídica», en MARCILLA, G. (ed.), Constitucionalismo y garantismo, Universidad Externado de Colombia, Bogotá, 2009, pp. 75-97.

58 Ferrajoli, L., Garantismo. Una discusión sobre Derecho y democracia, cit., p. 20.

${ }_{59}$ Marciani, B., «Sobre el concepto de derechos fundamentales de Luigi Ferrajoli», en Marcilla, G. (ed.), Constitucionalismo y garantismo, cit., pp. 164-166.

${ }^{60}$ Marciani, B., «Sobre el concepto de derechos fundamentales de Luigi Ferrajoli», cit., pp. 163-188. 
Derecho es uno de los deberes principales de una teoría jurídica de la democracia constitucional. Por esta razón, sin la satisfacción de los derechos sociales, los derechos políticos y los de libertad tienen la finalidad de permanecer en el papel. Lo que hacen es desarrollar, al lado de garantías negativas de corte liberal, un sistema social de garantías positivas con un sistema de funciones y de instituciones de garantías primarias y secundarias, dirigidas a la satisfacción de los derechos sociales y a su tutela jurisdiccional.

Otro tipo de cuestión sobre la crisis de legalidad interna es la producida, sobre todo, por fenómenos de inflación legislativa junto al aumento del poder dispositivo de los tribunales, uniéndose la crisis de la legalidad constitucional con la pérdida del rol garantista de las Constituciones y el resquebrajamiento del sistema clásico de las fuentes del Derecho. Aparte de que la transformación de la forma democrática que pasa de ser el gobierno del pueblo al gobierno de las élites origina una escisión entre la titularidad y el ejercicio del poder.

Finalmente, se vislumbra además una crisis del Estado social, sustitutivo durante un periodo de tiempo del ideal de la democracia participativa real, completamente legitimada, por el de una posible igualdad de los individuos en el plano sustancial. De esta situación que encierra una problemática de muy distinta naturaleza económica, jurídica y política de transformación se deriva la sensación de que el constitucionalismo democrático atraviesa muy malos momentos ${ }^{61}$. Pero el desenvolvimiento y el progreso del Estado de Derecho y de la democracia sustancial consisten en el desarrollo de las garantías capaces de hacerlas realidad ${ }^{62}$.

En consecuencia, cabe decir que la triple crisis del Derecho corre el peligro de transformarse en una crisis de la democracia, ya que en todo caso aflora una crisis del principio de legalidad, resolviéndose el problema neoabsolutista del poder público que carece de límites y de controles. Ferrajoli pone de manifiesto que los derechos fundamentales y sus garantías dependen hoy de la crisis del Derecho plasmada en el caos normativo y la ilegalidad difusa, pero también de la crisis de la razón jurídica moderna materializada en su pérdida de confianza ${ }^{63}$.

${ }^{61}$ Pozzolo, S., «Breves reflexiones al margen del constitucionalismo democrático», trad. L. Córdova, en Carbonell, M. \& Salazar, P. (eds.), Garantismo. Estudios sobre el pensamiento jurídico de Luigi Ferrajoli, cit., p. 404.

62 Ferrajoli, L., «Pasado y futuro del Estado de Derecho», en Carbonell, M., Neoconstitucionalismo(s), Trotta, Madrid, 2009, pp. 13-29; FerRaJoli, L., Derecho y razón. Teoría del garantismo penal, trad. P. Andrés IBÁÑEz, A. Ruiz Miguel, J. C. BAyón, J. Terradillos \& R. Cantarero, Trotta, Madrid, 2011, p. 867.

${ }^{63}$ Ferrajoli, L., «Los derechos fundamentales en la teoría del Derecho», en CABO, A. de \& Pisarello, G. (eds.), Los fundamentos de los derechos fundamentales, cit., pp. 139 y ss.; Ferrajoli, L., El garantismo y la Filosofia del Derecho, cit., p. 18. 


\section{A MODO DE CONCLUSIÓN}

Desglosados los aspectos precedentes, se obtienen las ideas de que el interés jurídico se desenvuelve en base a una vinculación a conceptos jurídicos en apoyo de los derechos subjetivos y de las obligaciones. Las razones para entenderlo jurídicamente relevante son una conjunción de factores éticos, culturales, sociales, políticos, económicos, espaciales o temporales, cuya valoración se caracteriza por su mutabilidad ${ }^{64}$. Desde esta posición, las demandas de derechos que poseen una naturaleza social o política son reformulables en muchas ocasiones en términos de violación individualizada y concreta de un derecho personal y con una víctima determinada. No obstante, se advierte que, aun en el supuesto de que el caso no tenga naturaleza colectiva, sí lo habrán de tener sus efectos, por lo que en estos casos se ha de comprender que la actuación judicial tiene el sentido de garantizar de alguna manera cierta forma participativa en la esfera política ${ }^{65}$.

De ese modo, llevando a cabo un intento clasificador, Abramavovich establece una catalogación de supuestos en: Aquellos que consisten en las intervenciones judiciales que tienden a juridificar decisiones de política pública asumidas por el Estado sin entrar en la valoración de la propia política pública; las situaciones consistentes en que el tribunal examina la compatibilidad de la política pública con el estándar jurídico aplicable y, por lo tanto, su adaptabilidad para satisfacer el derecho en cuestión. Dentro del marco de los derechos económicos, sociales y culturales, un elemento básico para el éxito radica en la posibilidad de articular los distintos campos, de forma que la resolución del caso legal contribuya a transformar las deficiencias institucionales, las políticas públicas o las situaciones sociales que se encuentran en la raíz de todo el conflicto. Un tercer tipo puede centrarse en las situaciones en las que el Poder judicial se ve forzado a tomar una decisión ante la no acción del resto de los poderes públicos, esto siempre que el tribunal verifique que solo hay una medida posible para ser adoptada y, por eso, que se produzca una falta de alternatividad al respecto. Y una cuarta variante de intervención judicial se mantiene cuando solo se limita a declarar que la omisión del Estado es legítima sin disponer ninguna medida de reparación ${ }^{66}$.

Con los referentes citados, la conclusión a la que se llega es que debe haber un trabajo conjunto y complementario en el que la acción de los pode-

${ }^{64}$ ARE, M., Schemi giuridici e rapporti d'interessi, CEDAM, Padua, 1972, pp. 272 y ss.; ORNAGHI, L., Il concetto di interesse, Giuffrè, Milán, 1986, pp. 30 y ss.; y, más recientemente, AÑón, M. J. \& GARcía AÑón, J. (coords.), Lecciones de derechos sociales, Tirant lo Blanch, Valencia, 2002, pp. 130-131.

${ }_{65}$ Abramovich, V., "Acceso a la justicia y nuevas formas de participación en la esfera política», Estudios socio-jurídicos, n. ${ }^{\circ}$ 9, 2007, pp. 10-13.

${ }_{66}$ Abramovich, V., «Acceso a la justicia y nuevas formas de participación en la esfera política», cit., pp. 17 y ss. 
res no sea aislada sino que esté en permanente combinación. Estas estrategias legales complementarias tienen como punto de partida un enfoque procedimental. En consecuencia, dice Abramovich que «no se reclama una prestación ni se impugna directamente una política o medida que afecta a derechos, sino que se pretende garantizar las condiciones que hacen posible la adopción de procesos deliberativos de producción de normas legislativas o actos de administración» ${ }^{67}$.

Sin embargo, siendo realistas, fuera de que el Derecho administrativo conforme o no un ordenamiento autónomo, sus normas se dirigen a la expansión de la organización económica capitalista y a la desaparición de las fronteras, refiriéndose a los flujos financieros o al mercado de bienes y servicios. Así pues, desde los parámetros aducidos lo que he tratado de poner de manifiesto es que cada vez se estrechan más las fronteras entre los Derechos público y privado, y se percibe cómo las Administraciones públicas recurren progresivamente al Derecho privado. En definitiva, mi pretensión ha sido mostrar que en las dos esferas preocupan los mismos temas: la participación de los interesados, el acceso de los ciudadanos, los costes que imponen y su control por el Parlamento. Mas la pregunta de hasta dónde puede llegar tal sistema privado es difícil de constatar, observándose que el control estatal se está perdiendo; y que los conflictos que se presentan en la Administración y el Derecho administrativo son significativos ${ }^{68}$. Pero, aun así, creo que ha de quedar claro que ambos tienen mucho que hacer en la protección del interés general.

\section{BIBLIOGRAFÍA}

ABramovich, V., «Acceso a la justicia y nuevas formas de participación en la esfera política», Estudios socio-jurídicos, n. ${ }^{\circ}$ 9, 2007, pp. 9-33.

Alessi, R., Principi di diritto amministrativo, t. I, Giuffrè, Milán, 1971.

Alli, J. C., Derecho administrativo y globalización, Civitas, Madrid, 2004.

Aman, A. C. Jr., «The limits of Globalization and the Future of Administrative Law. From Government to Governance», Indiana Journal of Global Legal Studies, ${ }^{\circ}{ }^{\circ}$ 8, 2001, pp. 379-400.

AÑón, M. J., Necesidades y derechos. Un ensayo de fundamentación, Centro de Estudios Constitucionales, Madrid, 1994.

— \& GARCía AÑón, J. (coords.), Lecciones de derechos sociales, Tirant lo Blanch, Valencia, 2002.

${ }^{67}$ Abramovich, V., «Acceso a la justicia y nuevas formas de participación en la esfera política», cit., p. 28.

${ }^{68}$ Aman, A. C. Jr., "The Limits of Globalization and the Future of Administrative Law. From Government to Governance», Indiana Journal of Global Legal Studies, n. ${ }^{\circ}$, 2001, pp. 379 y ss.; BaKer, G. \& Chandler, D. (eds.), Global Civil Society. Contested Futures, Routledge, Londres-Nueva York, 2005; MiR, O., Globalización, Estado y Derecho. Las transformaciones recientes del Derecho administrativo, cit., pp. 240 y ss. 
ARE, M., Schemi giuridici e rapporti d'interessi, CEDAM, Padua, 1972.

ARNAUD, A.-J., Entre la modernidad y la globalización, trad. N. González Lajoie, Universidad Externado de Colombia, Bogotá, 2000.

— \& FARIÑAs, M. J., Sistemas jurídicos: Elementos para un análisis sociológico, trad. de la segunda parte R. Escudero, Universidad Calos III de Madrid-Boletín Oficial del Estado, Madrid, 2006.

Ayres, I. \& Braithwaite, J., Responsive Regulation: Trascending the Deregulation Debate, Oxford University Press, Nueva York, 1992.

Baker, G. \& Chandler, D. (eds.), Global Civil Society. Contested Futures, Routledge, Londres-Nueva York, 2005.

BARRY, N. (ed.), Limited Government, Individual Liberty and the Rule of Law, Selected Works of Arthur Asher Shenfield, E. Elgar, Cheltenham, 1998.

BECK, U., La sociedad del riesgo global. Hacia una nueva modernidad, trad. J. Navarro, D. Jiménez \& M. R. Borrás, Paidós, Barcelona, 2008.

— ¿Qué es la globalización? Falacias del globalismo, respuestas a la globalización, trad. B. Moreno \& M. R. Borrás, Paidós, Barcelona, 2008.

BeEn, S. I. \& Peters, R. S., Los principios sociales y el Estado democrático, trad. R. J. Vernengo, Edit. Universitaria de Buenos Aires, Buenos Aires, 1984.

BeladíEz, M., Los principios jurídicos, Tecnos, Madrid, 1994.

BoвbIO, N., «El análisis funcional del Derecho: tendencias y problemas», en BoBBIO, N., Contribución a la Teoría del Derecho, edic. de A. Ruiz Miguel, Debate, Madrid, 1990.

— Igualdad y libertad, trad. P. Aragón Rincón, Paidós-Instituto de Ciencias de la Educación de la Universidad Autónoma de Barcelona, Barcelona, 2000.

Bradley, A. W. \& Ewin, K. D., Constitutional and Administrative Law, Pearson Education Limited, Essex, 2007.

Calsamiglia, A., «Eficiencia y Derecho», Doxa, n. ${ }^{\circ} 4,1987$, pp. 267-287. 161-178.

CARBonell, M., «La garantía de los derechos sociales en la teoría de Luigi Ferrajolì, en CARbonell, M. \& Salazar, P (eds.), Garantismo. Estudios sobre el pensamiento jurídico de Luigi Ferrajoli, Trotta-Instituto de Investigaciones Jurídicas de la Universidad Nacional Autónoma de México, Madrid, 2009, pp. 171-207.

Casares, J., Voz «Interés», en Diccionario ideológico de la lengua española, G. Gili, Barcelona, 1992.

CóRdova, L. «Constitucionalismo democrático y orden global», en CARBOnELL, M. \& Salazar, P. (eds.), Garantismo. Estudios sobre el pensamiento jurídico de Luigi Ferrajoli, Trotta-Instituto de Investigaciones Jurídicas de la Universidad Nacional Autónoma de México, Madrid, 2009, pp. 447-461.

Delmas-Marty, M., Trois défis pour un droit mundial, Seuil, París, 1998.

Desdentado, E., La crisis de identidad del Estado administrativo. Privatización, huida de la regulación pública y administraciones independientes, Tirant lo Blanch, Valencia, 1999.

DíAz, E., Sociología y Filosofía del Derecho, Taurus, Madrid, 1993.

Esteve Pardo, J., Autorregulación. Génesis y efectos, Thomson-Aranzadi, Cizur Menor, 2002. 
EstéVEZ, J. A., «La globalización y las transformaciones del Derecho», en ZAPATERO, V. (ed.), Horizontes de la Filosofía del Derecho, Homenaje a Luis García San Miguel, vol. I, Universidad de Alcalá, Alcalá de Henares, 2002, pp. 311-320.

FARIA, J. E., El Derecho en la economía globalizada, trad. C. Lema, Trotta, Madrid, 2004.

FARIÑAS, M. J., Globalización, ciudadanía y derechos humanos, Dykinson, Madrid, 2004.

FERnÁNDEZ GARCÍA, E., «Estado, sociedad civil y democracia», en Asís RoIG, R. de, Fernández García, E., GonzÁlez Ayala, M. D., Llamas, Á. \& Peces-Barba, G., Valores, derechos y Estado a finales del siglo XX, Universidad Carlos III de Madrid-Dykinson, Madrid, 1996, pp. 93-94.

FERnÁndez Rodríguez, T. R., De la arbitrariedad de la Administración, Civitas, Madrid, 1999.

FERRAJOLI, L., «Criminalidad y globalización», trad. M. Carbonell, Boletín Mexicano de Derecho Comparado, n. ${ }^{\circ} 115,2006$, pp. 301-316.

- Garantismo. Una discusión sobre Derecho y democracia, trad. A. Greppi, Trotta, Madrid, 2009.

—Los derechos fundamentales en la teoría del Derecho», en CABO, A. de \& Pisarello, G. (eds.), Los fundamentos de los derechos fundamentales, trad. P. Andrés Ibáñez, A. de Cabo, M. Carbonell, L. Córdova, M. Criado \& G. Pisarello, Trotta, Madrid, 2009, pp. 139-196.

- «Los fundamentos de los derechos fundamentales», en CABO, A. de \& PISARELLO, G. (eds.), Los fundamentos de los derechos fundamentales, trad. P. Andrés Ibáñez, A. de Cabo, M. Carbonell, L. Córdova, M. Criado \& G. Pisarello, Trotta, Madrid, 2009, pp. 287-381.

- «Pasado y futuro del Estado de Derecho», en Carbonell, M., Neoconstitucionalismo(s), Trotta, Madrid, 2009, pp. 13-29.

— Derechos y garantías. La ley del más débil, trad. P. Andrés Ibáñez \& A. Greppi, Trotta, Madrid, 2010.

— El garantismo y la Filosofía del Derecho, trad. G. Pisarello, A. J. Estrada \& J. M. Díaz Martín, Universidad Externado de Colombia, Bogotá, 2010.

— Derecho y razón. Teoría del garantismo penal, trad. P. Andrés Ibáñez, A. Ruiz Miguel, J. C. Bayón, J. Terradillos \& R. Cantarero, Trotta, Madrid, 2011.

— Principia iuris. Teoría del Derecho y la democracia, trad. P. Andrés Ibáñez, J. C. Bayón, M. Gascón, L. Prieto \& A. Ruiz Miguel, Trotta, Madrid, vol. 2, 2011.

Furger, F., «Global Markets, New Games, New Rules: The Challenge of International Private Governance», en ApPelbaum, R. P., Felstiner, W. L. F. \& Gessner, V., Rules and Networks. The Legal Culture of Global Business Transactions, Hart Publishing, Oxford, 2001, pp. 201-248.

García-Pelayo, M., Las transformaciones del Estado contemporáneo, Alianza, Madrid, 2005.

GARCÍA De ENTERRÍA, E., La lucha contra las inmunidades del poder en el Derecho administrativo. (Poderes discrecionales, poderes de gobierno, poderes normativos), Civitas, Madrid, 1995.

- Democracia, jueces y control de la Administración, Civitas, Madrid, 2000.

García De Enterría, E. \& Fernández, T. R., Curso de Derecho administrativo, t. I, Civitas, Madrid, 1999. 
GARrido, M. I., La politica social de la familia en la Unión Europea, Dykinson, Madrid, 2000.

GASCÓN, M., «Principia iuris: caracterización de una teoría jurídica», en MARCILLA, G. (ed.), Constitucionalismo y garantismo, Universidad Externado de Colombia, Bogotá, 2009, pp. 75-97.

Gilbert, N. \& Terrell, P., Dimensions of Social Welfare Policy, Allyn \& Bacon, Needham Heights, 2002.

Giner, S., Sociología, Península, Barcelona, 2009.

GONZÁlez GARCíA, J. V., «Globalización económica, Administraciones públicas y Derecho administrativo», Revista de Administración Pública, n. ${ }^{\circ}$ 164, 2004, pp. 7-40.

Guasp, J., Derecho, Gráficas Hergón, Madrid, 1971.

Habermas, J., Conocimiento e interés, trad. M. Jiménez Redondo, Universidad de Valencia, Valencia, 1995.

Head, M., Administrative Law. Context and Critique, The Federation Press, Sydney, 2008.

Heck, P., El problema de la creación del Derecho, trad. M. Entenza, Comares, Granada, 1999.

Hierro, L., Justicia, igualdad y eficiencia, Centro de Estudios Políticos y Constitucionales, Madrid, 2002.

Julios-CAmpuzANo, A. de, «La crisis del ordenamiento. Reflexiones sobre racionalidad jurídica y globalización», en Julios-CAmpuzano, A. de (ed.), Ciudadanía y Derecho en la era de la globalización, Dykinson, Madrid, 2007.

LATORRe, Á., Introducción al Derecho, Ariel, Barcelona, 2006.

Lima, J., «Globalización y derechos humanos», Anuario de Filosofía del Derecho (España), t. XVII, 2000, pp. 43-73.

López Guerra, L., «Las dimensiones del Estado social de Derecho», Sistema, n. ${ }^{\circ}$ 38-39, 1980, pp. 171-192.

MARCIANI, B., «Sobre el concepto de derechos fundamentales de Luigi Ferrajoli», en Marcilla, G. (ed.), Constitucionalismo y garantismo, Universidad Externado de Colombia, Bogotá, 2009, pp. 163-188.

MArcilla, G., «Desregulación, Estado social y proceso de globalización», Doxa, n. ${ }^{\circ}$ 28, 2005, pp. 239-263.

Merton, R. K., Social Theory and Social Structure, Free Press, Glencoe, 1968.

Mir, O., Globalización, Estado y Derecho. Las transformaciones recientes del Derecho administrativo, Civitas, Madrid, 2004.

Montoro, M. J., La evaluación de las normas. Racionalidad y eficiencia, Atelier, Barcelona, 2001.

Navarro, P. E. \& Redondo, M. C., Normas y actitudes normativas, Fontamara, México, 2000.

Nino, C. S., Un país al margen de la ley. Estudio de la anomia como componente del subdesarrollo argentino, Ariel, Buenos Aires, 2005.

ORNAGHI, L., Il concetto di interesse, Giuffrè, Milán, 1986.

PÉrez Luño, A. E., Derechos humanos, Estado de Derecho y Constitución, Tecnos, Madrid, 2005.

Pozzolo, S., «Breves reflexiones al margen del constitucionalismo democrático», trad. L. Córdova, en Carbonell, M. \& Salazar, P. (eds.), Garantismo. Estudios sobre el pensamiento jurídico de Luigi Ferrajoli, Trotta-Instituto de Investigaciones Jurídicas de la Universidad Nacional Autónoma de México, Madrid, 2009, pp. 403-427. 
PRIETO, L., Ley, principios, derechos, Dykinson, Madrid, 1998.

RÚA, C., «La legitimidad en el ejercicio del poder político en el Estado social de Derecho. Una revisión desde el caso colombiano», Ius et Praxis, n. ${ }^{\circ}$ 2, 2013, pp. 85-122.

SAINZ, F., Conceptos jurídicos, interpretación y discrecionalidad administrativa, Civitas, Madrid, 1976.

Smart, P., Mill and Marx, Individual Liberty and the Roads to Freedom, Manchester University Press, Manchester 1991.

Sousa Santos, B. de, Toward a New Common Sense: Law, Science and Politics in the Paradigmatic Transition, Routledge, Londres, 1995.

Stiglitz, J. E., El malestar en la globalización, trad. C. Rodríguez Braun, Taurus, Madrid, 2010.

Treves, R., La Sociología del Derecho. Orígenes, investigaciones, problemas, trad. M. Atienza, Ariel, Barcelona, 1998.

TuOri, K., Positivismo crítico y Derecho moderno, trad. D. Mena, Fontamara, México, 2005.

VIDAL, E. J., Los conflictos de derechos en la legislación y jurisprudencia españolas. Un análisis de algunos casos difíciles, Tirant lo Blanch, Valencia, 1999.

Zagrebelsky, G., El Derecho dúctil. Ley, derechos, justicia, trad. M. Gascón, Trotta, Madrid, 2009.

Zapatero, V., Garrido, M. I. \& Arcos, F., El arte de legislar, Thomson-Aranzadi, Cizur Menor, 2009.

- \& GARRIDO, M. I., El Derecho como proceso normativo. Lecciones de Teoría del Derecho, Universidad de Alcalá, Alcalá de Henares, 2010.

TITLE: The protection of the general interests by the Administration and the Administrative Law. (A study from the perspective of the juridical theory and the political philosophy).

RESUMEN: En este trabajo, pretendo dar cuenta de los importantes cambios que ha sufrido la protección del interés público. No obstante, y como se intentará demostrar, esos cambios no se producen por una evolución progresiva y cuasinatural del contexto sociológico, económico, político oly jurídico, sino que surgen por la irrupción de una nueva situación en la que la globalización tiene mucho que decir. Asumiendo lo anterior, mostraré la relevante influencia que ha supuesto el fenómeno globalizador, todo ello desde la perspectiva de la Teoría jurídica y de la Filosofía política. A partir de estas premisas, me adentraré en la situación del Derecho administrativo vigente y de las garantías del interés general en los Estados de Derecho contemporáneos; y analizaré el juego de los límites a la Administración en la protección del interés general. Por último, llegaré a la conclusión de que, por muchas mutaciones que se produzcan, dicho interés debe seguir protegiéndose y, desde luego, ahi la Administración y el Derecho administrativo deben seguir prestando una importante función, si bien adaptada a los nuevos tiempos.

PALABRAS CLAVE: Protección del interés general-Administración-Derecho administrativo. 
ABSTRACT: In this paper I intend to give an account of the major changes undergone by the protection of the public interest. However, as I will try to show, these changes are not caused by a progressive and quasi-natural evolution of sociological, economic, political and/or legal context, but arise from the emergence of a new situation in which globalization has much to say. Assuming the aforesaid, I'll show the significant influence that the phenomenon of globalization has had, all from the perspective of Legal theory and Political philosophy. From these premises, I shall go in depth on the current situation of Administrative Law and the guarantees of public interest in contemporary rule of law; and analyze how the government is limited in its protection of the public interest. Finally, the conclusion is reached that, no matter how many changes occur, such interest must continue to be protected and, of course, there the government and Administrative Law should continue to provide an important role, although changed with the times.

KEYWORDS: Protection of public interest - Administration - Administrative Law.

RECIBIDO: 01.07.2014

ACEPTADO: 26.11.2014 